\title{
Amplified electrochemcial determination of maltol in food based on graphene oxide-wrapped tin oxide@ carbon nanospheres
}

Tian Gan ${ }^{\text {a,b, }}$, Junyong Sun ${ }^{\text {a }}$, Miaomiao Yu ${ }^{\text {a }}$, Kaili Wang ${ }^{\text {a }}$, Zhen Lv ${ }^{\text {a, }}$, Yanming Liu $\mathrm{a}, \mathrm{b}, *$

a College of Chemistry and Chemical Engineering, Xinyang Normal University, Xinyang 464000, China

${ }^{\mathrm{b}}$ Institute for Conservation and Utilization of Agro-bioresources in Dabie Mountains, Xinyang Normal University, Xinyang 464000, China

\begin{abstract}
The study presents a new approach for rapid and ultrasensitive detection of maltol using a glassy carbon electrode (GCE) modified with graphene oxide-wrapped tin oxide@carbon nanospheres $\left(\mathrm{SnO}_{2} @ \mathrm{C} @ \mathrm{GO}\right)$. The morphological and components properties of $\mathrm{SnO}_{2} @ \mathrm{C} @ \mathrm{GO}$ nanocomposites were investigated by means of $\mathrm{X}$-ray diffraction spectroscopy, Raman spectroscopy, field emission scanning electron microscopy, high resolution transmission electron microscopy, and electrochemical impedance spectroscopy. $\mathrm{SnO}_{2} @ \mathrm{C} @ \mathrm{GO}$ nanocomposite on a GCE had a synergetic effect on the electrochemical oxidation of maltol by means of square wave voltammetry. Under the optimum conditions, anodic peak current response of maltol was linear with its concentration in the range of $80 \mathrm{nM} \sim 10 \mu \mathrm{M}$, and a detection limit of $12 \mathrm{nM}$ was achieved for maltol. The experiment results presented that the method showed good selectivity, sensitivity, reproducibility, and long-term stability, as well as excellent potential for use as an ideal inexpensive voltammetric method applicable
\end{abstract}

\footnotetext{
* Corresponding authors at: College of Chemistry and Chemical Engineering, Xinyang Normal University, Xinyang 464000, China.

E-mail address: gantianxynu@163.com (T. Gan).
} 
for complex food matrices.

Keywords: Maltol, Graphene oxide, Tin oxide, Carbon, Electrochemical method Chemical compounds studied in this article

Maltol (PubChem CID: 8369); Tin oxide (PubChem CID: 29011); Carbon (PubChem CID: 5462310); Potassium ferricyanide (PubChem CID: 26250); Glucose (PubChem CID: 5793); Sucrose (PubChem CID: 5988); Glycine (PubChem CID: 750); Citric acid (PubChem CID: 311); Tartaric acid (PubChem CID: 444305); Hydrogen peroxide (PubChem CID: 784); Ascorbic acid (PubChem CID: 54670067); Hydroquinone (PubChem CID: 785)

\section{Introduction}

Flavor enhancers are important sensory attribute which play important roles in the palatability, taste and acceptability of food, so they are widely used as food additives to enhance the flavor of beverages and foods [Dermiki, Phanphensophon, Mottram, \& Methven, 2013]. Therein, maltol (3-hydroxy-2-methyl-4H-pyran-4-one) is a naturally occurring flavor enhancer widely used in food products at levels ranging from 50 to $200 \mathrm{mg} \mathrm{kg}^{-1}$ [LeBlanc \& Akers, 1989]. However, maltol has been suspected of having potential harmful consequences on brain, liver, kidney, and spleen functions of the baby when large amount of this enhancer is ingested [Ni, Zhang, \& Kokot, 2005]. Considering the adverse effects of maltol, the regulations of the Food and Drug Administration (FDA) and China National Food Safety Standard have forbidden its use in children food and it is not allowed at all in the European Union [Ma, Zhang, Wang, Hou, \& He, 2014]. Therefore, the sensitive and convenient analysis of maltol is a potentially important test case in food quality control. 
To allow quantitation of maltol at subthreshold concentration, the analytical method has to be highly sensitive, selective, and reliable. Different methods such as gas chromatography-mass spectrometry [Qi \& Zhou, 2005], spectrometry [Ni, Wang, \& Kokot, 2008], high-performance liquid chromatography [Risner \& Kiser, 2008] and two-dimensional liquid chromatography [Avila, Gonzalez, Zougagh, Escarpa, \& Rios, 2007] have been reported in the literature, mostly utilizing complex, expensive and time-consuming techniques. Furthermore, many electrochemical methods have previously been developed for the determination of maltol [Chao \& Ma, 2014; Ma \& Chao, 2014; Ma \& Chao, 2013; Zhou, Zhang, Li, Li, \& Ye, 2012; Di, Bi, \& Zhang, 2004], it can be concluded that the sensing layers of electrode are crucial, so more research is still in process.

As a typical $\mathrm{n}$-type semiconductor, nano-sized tin oxide $\left(\mathrm{SnO}_{2}\right)$ including $\mathrm{SnO}_{2}$ nanosphere has become one of the major focuses semiconducting metal oxides because of the unique electronic, catalytic, and optical properties [Ahn, Kim, Chi, \& Kim, 2014; Escuderos, Garcia, Jimenez, \& Horrillo, 2013], as well as their simple fabrication, good compatibility, and high natural abundance. And also, $\mathrm{SnO}_{2}$ based chemical sensors have been investigated. However, such sensors based on $\mathrm{SnO}_{2}$ usually perform high power consumption and adversely affect the long-term stability, which are still the major challenges for $\mathrm{SnO}_{2}$ to meet the practical application requirements. Thus, some attempts have been made to overcome these innate shortcomings, by decorating the $\mathrm{SnO}_{2}$ with thin and intact shells such as carbonaceous materials. We have developed functional carbonaceous materials with conjugative $\pi$ structure to enhance the electrocatalytic activity of semiconductors [Gan, Shi, Wang, Sun, Lv, \& Liu, 2016; Gan, Shi, Hu, Sun, Wang, \& Liu, 2015; Huang et al., 2013]. In particular, it has been demonstrated successfully by different groups including ours 
that growing a layer of carbon on the surface of metal oxides improves their electrochemical properties. For example, the study of Liu et al showed that the conductive carbon layer endowed the $\mathrm{SnO}_{2}$-based anode with improved specific capacity and cycling stability, making it more promising for use in lithium ion batteries [Liu, Dou, Ruan, Sun, Chou, \& Dou, 2016]. Qu et al found the carbon crystallite on $\mathrm{SnO}_{2}$ grain boundary could improve the sensitivity and selectivity of $\mathrm{SnO}_{2}$ material for gas sensing, as well as reduce the sensing temperatures and the response time because the catalytic effect and electron donor of carbon crystallite $[\mathrm{Qu}$, Wang, Chen, Han, \& Lin, 2016]. First, the carbon matrix can accommodate the volume variations of $\mathrm{SnO}_{2}$ core and avoid its pulverization. Second, the carbon shell can enhance the electrode conductivity, resulting a high reversible capacity. Third, the carbon with inert nature is less harmful under physiological/environmental conditions [Zhang, Wang, Zhang, Shao, Hu, \& Shao, 2015]. Therefore, the $\mathrm{SnO}_{2} @$ carbon $\left(\mathrm{SnO}_{2} @ \mathrm{C}\right)$ hybrid nanoparticles (NPs) may retain the properties of individual components and further enhanced properties (such as optical, electrical, and catalytic property) and even present new synergistic effect.

Recently, the wrapping of a two-dimensional (2D) carbonaceous matrix outside core-shell NPs was shown to be a highly effective approach to enhance the conductivity and structural stability of core-shell NPs-based electrode materials [Gan, Lv, Sun, Shi, \& Liu, 2016]. In this work, we synthesized $\mathrm{SnO}_{2} @ \mathrm{C}$ by hydrothermal carbonization of glucose in the presence of sodium stannate, and subsequent functionalization by $2 \mathrm{D}$ graphene oxide (GO). In such a sandwich like architecture, the volume expansion of the enwrapped $\mathrm{SnO}_{2}$ NPs can be greatly controlled by the carbon shells. Moreover, the intimate contact between $\mathrm{GO}$ and $\mathrm{SnO}_{2} @ \mathrm{C}$ is favorable for accessibility to analytes and rapid diffusion of electrons. And further, a new 
modified electrode was constructed by immobilization of the $\mathrm{SnO}_{2} @ \mathrm{C} @ \mathrm{GO}$ nanocomposite on a glassy carbon electrode (GCE) surface. The resulting modified electrode was successfully applied to the determination of maltol in food samples with amplified electrochemical response and satisfactory recovery, which showed many merits such as easy fabrication, low cost, high sensitivity, and good reproducibility.

\section{Experimental section}

\subsection{Chemicals and apparatus}

Graphite flakes, nitric acid $\left(\mathrm{HNO}_{3}\right)$, sulfuric acid $\left(\mathrm{H}_{2} \mathrm{SO}_{4}\right)$, potassium permanganate $\left(\mathrm{KMnO}_{4}\right)$, 3-aminopropyltrimethoxysilane (APTES), glucose and sodium stannate monohydrate $\left(\mathrm{Na}_{2} \mathrm{SnO}_{3} \cdot \mathrm{H}_{2} \mathrm{O}\right)$ were obtained from Sinopharm Chemical Reagent Co., Ltd. Maltol was obtained from Aladdin Industrial Inc. All reagents were of analytical grade. The buffer involved in this work was boric acid-borax buffer ( $\mathrm{pH}$ 8.2). All chemicals in this work were used as received without further purification. Deionized water was used throughout the study.

The CHI 660D electrochemical workstation (Chenhua Instrument Limited Company, Shanghai, China), a traditional three-electrode system containing saturated calomel electrode (SCE) as the reference electrode, Pt wire as the counter electrode, and $3 \mathrm{~mm} \mathrm{GCE}$ as the working electrode were used for electrochemical measurements. Powder X-ray diffraction patterns (XRD) of samples were recorded using a Rigaku $\mathrm{D} / \mathrm{Max}-\mathrm{rC}$ powder diffractometer in the $2 \theta$ range of $10-80^{\circ}$ with a $2 \theta$ step size of $0.01^{\circ}$ and step time of 2 s. Raman spectra measurements were carried out on a micro-Raman spectrometer (Witech CRM200, the excitation wavelength at $532 \mathrm{~nm}$ ). Scanning electron microscope (SEM) images were conducted on a Hitachi S-4800 
instrument operating at $20 \mathrm{kV}$. Transmission electron microscope (TEM) images were obtained with a field-emission transmission electron microscope at an accelerating voltage of $200 \mathrm{kV}$ (Tecnai G220 S-Twin, FEI Company, Netherlands).

\subsection{Synthesis of $\mathrm{SnO}_{2} @ C @ G O$ nanocomposite}

In a typical synthesis of $\mathrm{SnO}_{2} @ \mathrm{C}$ core-shell nanospheres [Hu, Yan, Shen, \& Zhong, 2012], $4.0 \mathrm{~g}$ glucose and $0.214 \mathrm{~g} \mathrm{Na}_{2} \mathrm{SnO}_{3} \cdot \mathrm{H}_{2} \mathrm{O}$ were dissolved in $40 \mathrm{~mL}$ water for 10 min. The aqueous solution was then transferred to a $50 \mathrm{~mL}$ Teflon-lined stainless steel autoclave, which was heated at $160{ }^{\circ} \mathrm{C}$ for $15 \mathrm{~h}$. Afterward, the precipitates were separated by means of centrifugation at $4,000 \mathrm{rpm}$ for $10 \mathrm{~min}$. The product was washed six times with water and ethanol alternately, and dried in a vacuum oven at $70{ }^{\circ} \mathrm{C}$ for $12 \mathrm{~h}$.

For the synthesis of highly conducting GO, a mild bulk synthesis approach was used [Kumar et al., 2015]. Firstly, tattered graphite was obtained by refluxing graphite flakes in concentrated $\mathrm{HNO}_{3}$ for $24 \mathrm{~h}$ followed by washing with water and drying. This tattered graphite $(1 \mathrm{~g})$ was ground together with $\mathrm{KMnO}_{4}$ until homogeneous. Concentrated $\mathrm{H}_{2} \mathrm{SO}_{4}(98 \%, 30 \mathrm{~mL})$ was introduced into a $250 \mathrm{~mL}$ flask immersed in ice- bath, then the above mixture of tattered graphite and $\mathrm{KMnO}_{4}$ was added pinch by pinch under vigorous stirring over $30 \mathrm{~min}$. When the addition was completed, ice bath was removed and stirring was continued at room temperature till the volumetric expansion was once observed (about $30 \mathrm{~min}$ ). The flask was placed in an ice-bath again and $120 \mathrm{~mL}$ water was added with rapid stirring. The temperature of the bath was raised to $90{ }^{\circ} \mathrm{C}$ and the stirring was kept for $1 \mathrm{~h}$ to obtain a homogeneous black suspension. Afterwards, the precipitates were separated by means of centrifugation at $12,000 \mathrm{rpm}$ for $20 \mathrm{~min}$ and washed with water-methanol mixture $(1: 1, \mathrm{~V} / \mathrm{V})$ for 
several times until $\mathrm{pH}$ was neutral. In order to fully exfoliate the GO sheets, the obtained precipitates were further suspended in water and ultrasonicated for $12 \mathrm{~h}$.

GO was wrapped outside $\mathrm{SnO}_{2} @ \mathrm{C}$ core-shell nanospheres through electrostatic attraction. Firstly, 0.2 g SnO $2 @ \mathrm{C}$ nanospheres were dispersed into $100 \mathrm{~mL}$ ethanol through ultrasonication. Then $1 \mathrm{~mL}$ APTES was added and refluxed for $5 \mathrm{~h}$ to get amine-functionalized $\mathrm{SnO}_{2} @ \mathrm{C}$ nanospheres. The products were separated by means of centrifugation at 4,000 rpm for $10 \mathrm{~min}$ and rinsed with ethanol to wash away the unreacted APTES. After that, $30 \mathrm{~mL}$ of $\mathrm{GO}$ aqueous solution $\left(1 \mathrm{mg} \mathrm{mL}^{-1}\right)$ was added and the mixture was stirred vigorously for 1 h. Finally, the resulting $\mathrm{SnO}_{2} @ \mathrm{C} @ \mathrm{GO}$ was filtered, washed with water and ethanol several times, and redispersed into $5 \mathrm{~mL}$ water. The schematic illustration of the synthesis is presented in Fig. 1.

\subsection{Electrode modification}

Prior to modification, GCE was subsequently polished with 1.0 and $0.05 \mu \mathrm{m}$ alumina powder on polishing cloth and sonicated successively in water-ethanol mixture $(1: 1, \mathrm{~V} / \mathrm{V})$ and water in order to remove adsorbed particles. The procedure for the fabrication of $\mathrm{SnO}_{2} @ \mathrm{C} @ \mathrm{GO} / \mathrm{GCE}$ was conducted by casting $10 \mu \mathrm{L}$ of $\mathrm{SnO}_{2} @ \mathrm{C} @ \mathrm{GO}$ suspension on the pretreated GCE surface and allowed to dry under an infrared lamp in the air.

\subsection{Food samples preparation}

The crispness biscuit, black beer, Cabernet Sauvignon red wine and orange juice samples were purchased from local market. Among them, the beer, red wine and juice samples were used directly, but biscuit sample was used after pretreatment. In an agate mortar, $10 \mathrm{~g}$ of biscuit sample was ground to powder, which was then stirred 
with $150 \mathrm{~mL}$ absolute ethanol for $30 \mathrm{~min}$. The filtrate of the solution was collected after being vacuum filtered and diluted in $50 \mathrm{~mL}$ volumetric flasks using water.

\subsection{Determination of maltol}

Maltol determination was performed by using boric acid-borax buffer with $\mathrm{pH} 8.2$ as supporting electrolyte. After a $60 \mathrm{~s}$ accumulation time under open circuit and $5 \mathrm{~s}$ of quiet time, the square wave voltammograms were recorded from 0.10 to $0.90 \mathrm{~V}$, and the oxidation peak current at $0.55 \mathrm{~V}$ was measured for maltol. The amplitude was 25 $\mathrm{mV}$, the frequency was $15 \mathrm{~Hz}$, and the scan rate was $40 \mathrm{mV} \mathrm{s}^{-1}$.

\section{Results and discussion}

\subsection{Characterizations}

The structures of the as-prepared $\mathrm{SnO}_{2} @ \mathrm{C} @ \mathrm{GO}$ nanocomposite were identified with XRD, as shown in Fig. 2A. The diffraction peaks at $2 \theta$ values of $26.4^{\circ}$ (110), $33.7^{\circ}(101), 37.7^{\circ}(200), 51.6^{\circ}(211), 54.2^{\circ}(220), 58.3^{\circ}(002), 61.5^{\circ}(310), 65.2^{\circ}$ (112), $71.3^{\circ}(202)$ and $78.3^{\circ}(321)$ are consistent with the standard XRD data for the tetragonal rutile like $\mathrm{SnO}_{2}$ phase (JCPDS File no. 41-1445). The mean crystal size calculated for $\mathrm{SnO}_{2}$ nanoparticles that assemble into the $\mathrm{SnO}_{2}$ core is found to be 7.6 $\mathrm{nm}$ by using the Scherrer equation. Besides, the peak at $2 \theta=10.4^{\circ}$ is in agreement with the (001) reflection of GO with an interlayer spacing of $0.81 \mathrm{~nm}$. The results prove that $\mathrm{SnO}_{2}$ nanoparticles coexist with $\mathrm{GO}$ sheets. Above all, no other impurity peaks are detected, indicating the high purity of the products.

Raman analysis, which provides information about atomic structure, is particularly useful for characterizing carbon-based materials. Fig. 2B shows the Raman spectra of 
$\mathrm{SnO}_{2} @ \mathrm{C}$ (a) and $\mathrm{SnO}_{2} @ \mathrm{C} @ \mathrm{GO}$ (b) hybrid materials that contain a strong band at $\sim 1590 \mathrm{~cm}^{-1}$ ( $\mathrm{G}$ band) and a weak band at $\sim 1350 \mathrm{~cm}^{-1}$ (D band). The $\mathrm{G}$ band in Raman spectra is well known to represent the $\mathrm{E}_{2 \mathrm{~g}}$ vibrational mode of $\mathrm{sp}^{2}$-bonded graphitic carbon, and the $\mathrm{D}$ band is attributed to disordered structures resulting from atomic-scale defects on the graphitic plane [Maslova, Ammar, Guimbretiere, Rouzaud, \& Simon, 2012]. A strong G band such as that can be seen in Fig. 2B often denotes an abundance of ordered carbon atoms in carbonaceous materials. The degree of crystallinity can also be quantified from the Raman spectrum by using the ratio of $I_{\mathrm{D}} / I_{\mathrm{G}}$, where $I_{\mathrm{D}}$ and $I_{\mathrm{G}}$ are the integrated intensities of the $\mathrm{D}$ and $\mathrm{G}$ band, respectively. The value of $I_{\mathrm{D}} / I_{\mathrm{G}}$ calculated from curve a is relatively large at 0.67 , implying a low degree of crystallinity as compared to that of crystalline graphite $\left(I_{\mathrm{D}} / I_{\mathrm{G}}=0.1-0.3\right)$ [Matthews, Pimenta, Dresselhaus, Dresselhaus, \& Endo, 1999]. When GO is further wrapped outside of the $\mathrm{SnO}_{2} @ \mathrm{C}$ spheres, the D/G intensity ratio increases to 0.82 due to the oxygen functional groups in the GO sheets. However, the observed $I_{\mathrm{D}} / I_{\mathrm{G}}$ of $\mathrm{SnO}_{2} @ \mathrm{C} @ \mathrm{GO}$ in our work is much lower than that of graphene based materials in other literatures [Zhou, Li, Sun, \& Yang, 2016; Huang, Shuai, \& Zhang, 2016], implying the low $\mathrm{sp}^{2} \mathrm{C}-$ network rupture, long range ordering and high enough electrical conductivity of graphene sheets, which originates from the mild oxidation process of graphite to prepare GO. The positive shifting in $\mathrm{G}$ band peak position compared with pristine graphene can be addressed to the hybridization of GO with an electron acceptor component (amino-functionalized $\mathrm{SnO}_{2} @ \mathrm{C}$ ) [ Zhu, Chen, \& Liu, 2012], which can modify the electronic structure of GO by stiffening or softening of phonons and give rise to the shift of Fermi energy level [Das, Voggu, Routa, \& Rao, 2008; Voggu, Rout, Franklin, Fisher, \& Rao, 2008]. Next to the G band shows the D' band which is due to the presence of disorder (Fig. 2B, curve b). This band is 
dispersive in the frequency because of the double resonant scattering [Thomsen, \& Reich, 2000; Maslova et al., 2012], however, the relative intensity of this band is usually low. In addition, the $\mathrm{SnO}_{2} @ \mathrm{C} @ \mathrm{GO}$ samples produce a distinct 2D band at around $2700 \mathrm{~cm}^{-1}$ in their Raman spectra (Fig. 2B, curve b), which arises from the second order of zone-boundary phonons [Jiang et al., 2011], and S3 peak near 2950 $\mathrm{cm}^{-1}$ shows up which can be attributed to the lattice disorders with its number of Raman shift roughly the combination of the $\mathrm{G}$ and $\mathrm{D}$ peaks. The $2 \mathrm{D}$ band shifts to a higher frequency $\left(2700 \mathrm{~cm}^{-1}\right)$ from the typical peak $\left(2679 \mathrm{~cm}^{-1}\right)$ of a single layer structure, indicating the possible multilayer structure of GO samples wrapped outside of $\mathrm{SnO}_{2} @ \mathrm{C}$ spheres.

Morphology of the as-prepared samples were investigated by SEM and TEM images, as shown in Fig. 3. The SEM image in Fig. 3a shows that the size of $\mathrm{SnO}_{2} @ \mathrm{C}$ nanospheres prepared by our one-pot method is quite uniform. From the magnification image (Fig. 3b), sphere-like morphology with the average size of 68 $\mathrm{nm}$ is observed, which can be assigned to the 3D structure of the $\mathrm{SnO}_{2} @ \mathrm{C}$. To better understand the core-shell structure, the obtained sample can be further confirmed by TEM (Fig. 3c,d). TEM image shows that $\mathrm{SnO}_{2}$ cores (dark spots in Fig. 3c) with uniform sizes $(\sim 58 \mathrm{~nm})$ are assembled by numerous $\mathrm{SnO}_{2}$ nanoparticles $(\sim 7.6 \mathrm{~nm})$, and these $\mathrm{SnO}_{2}$ cores are further effectively encapsulated within the well-proportioned spherical carbon $(\sim 10 \mathrm{~nm})$. To study the detailed lattice structure, the high-resolution TEM image was carried out. The interplanar distance is $0.337 \mathrm{~nm}$, corresponding to the (110) plane of rutile $\mathrm{SnO}_{2}$ (Fig. 3d). Furthermore, Fig. 3e and $\mathrm{f}$ show the TEM images of $\mathrm{SnO}_{2} @ \mathrm{C} @ \mathrm{GO}$ ternary architecture. Clearly, the 2D, free-standing GO with thin stacked flakes and layered structure at the edge can be seen in Fig. 3e, which is flat but crumpled. In addition, the core-shell structure of 
$\mathrm{SnO}_{2} @ \mathrm{C}$ is well maintained. And the high-magnification TEM image of $\mathrm{SnO}_{2} @ \mathrm{C} @ \mathrm{GO}$ is shown in Fig. 3f. It is apparent that $\mathrm{SnO}_{2} @ \mathrm{C}$ nanospheres are well wrapped by the transparent GO textures because of interfacial interactions. The wrapping of $\mathrm{SnO}_{2} @ \mathrm{C}$ nanospheres with $\mathrm{GO}$ can be explained by the electrostatic interaction of the $-\mathrm{OH}$ and $-\mathrm{COOH}$ functional groups of $\mathrm{GO}$ with the surface of amino-functionalized $\mathrm{SnO}_{2} @ \mathrm{C}$. Notably, the intimate contact between conductive GO sheets and $\mathrm{SnO}_{2} @ \mathrm{C}$ nanospheres can not only enhance the conductivity of overall electrode but also is favourable to the transfer of electrons to active $\mathrm{SnO}_{2} @ \mathrm{C}$ materials.

Electrochemical impedance spectroscopy (EIS) is a tool to evaluate the electron transfer resistance, which was carried out to investigate the conductivity of the modified electrode. Supplemental Fig. S1 shows the Nyquist plots recorded for bare GCE, $\mathrm{SnO}_{2} @ \mathrm{C} / \mathrm{GCE}$ and $\mathrm{SnO}_{2} @ \mathrm{C} @ \mathrm{GO} / \mathrm{GCE}$ in a $5 \mathrm{mM} \mathrm{K}_{3} \mathrm{Fe}(\mathrm{CN})_{6}$ solution with $0.1 \mathrm{M} \mathrm{KCl}$ as the supporting electrolyte. The Randles equivalent circuit simulating with ZSimWin software in the inset of Supplemental Fig. S1 includes the resistance of solution $\left(R_{\mathrm{s}}\right)$, the double layer capacitance $\left(C_{\mathrm{dl}}\right)$, the electrode transfer resistance $\left(R_{\mathrm{et}}\right)$ and the Warburg impedance $\left(Z_{\mathrm{w}}\right)$. The modification of the electrode surface only affects the value of $R_{\mathrm{et}}$, which denotes the semicircle diameter of the Nyquist plots and is an appropriate signal exhibiting the interfacial natures of the modified electrodes. The EIS result of GCE modified by $\mathrm{SnO}_{2} @ \mathrm{C}$ shows that the $R_{\mathrm{et}}$ greatly decreases from 1566.3 (curve a) to $763.1 \Omega$ (curve b). This effect is attributed to $\mathrm{SnO}_{2} @ \mathrm{C}$ core-shell structured nanospheres, which serve as a good-conducting layer and increase the interfacial electron transfer between the electrode and the $\mathrm{K}_{3} \mathrm{Fe}(\mathrm{CN})_{6}$ probe. When the $\mathrm{SnO}_{2} @ \mathrm{C} @ \mathrm{GO}$ is coated on the surface of GCE (curve c), an interfacial electron transfer is further accelerated, which leads to a significant decrease 
of $R_{\text {et }}$ value $(\sim 381.5 \Omega)$. Such improved performance is the result of a synergistic effect arising from the interactions between $\mathrm{SnO}_{2}$ and carbon as well as between $\mathrm{SnO}_{2} @ \mathrm{C}$ and GO. In such hybrid systems, the $\mathrm{SnO}_{2} @ \mathrm{C}$ not only provides a high catalytic ability, but also serves as a nanospacer to maintain the adjacent GO sheets separated to minimize the agglomeration of GO sheets.

\subsection{Electrochemical behavior of maltol}

The electrochemical behavior of maltol was investigated at different modified electrodes using cyclic voltammetry $(\mathrm{CV})$ in $\mathrm{pH} 8.2$ boric acid-borax buffer. Supplemental Fig. S2 shows cyclic voltammograms recorded at bare GCE and $\mathrm{SnO}_{2} @ \mathrm{C} @ \mathrm{GO} / \mathrm{GCE}$ in the absence and in the presence of $10 \mu \mathrm{M}$ maltol at a scan rate of $100 \mathrm{mV} \mathrm{s}^{-1}$. As shown in curve a, a tiny peak with the oxidation peak potential at about $0.58 \mathrm{~V}$ is clearly observed on bare GCE, suggesting that the oxidation activity of maltol is very low on the bare GCE surface. Interestingly, the oxidation peak increases significantly on the surface of $\mathrm{SnO}_{2} @ \mathrm{C} @ \mathrm{GO}-$ modified GCE (curve b), indicating that the prepared $\mathrm{SnO}_{2} @ \mathrm{C} @ \mathrm{GO}$ is more active for the oxidation of maltol. Compared with bare GCE, $\mathrm{SnO}_{2} @ \mathrm{C} @ \mathrm{GO}$ ternary core-shell material is proven to own larger electrode area and faster electron transfer rate, therefore, the oxidation activity of maltol is improved obviously on $\mathrm{SnO}_{2} @ \mathrm{C} @ \mathrm{GO}$ surface. In addition, it is obvious that the oxidation peak current of maltol decreases markedly during the second and third anodic sweeps. This phenomenon manifests the strong adsorption of oxidation product of maltol on electrode surface. Consequently, the oxidation peak current in the first anodic sweep is recorded for the analysis of maltol to achieve high sensitivity. Additionally, the CV responses of bare GCE (curve c) and $\mathrm{SnO}_{2} @ \mathrm{C} @ \mathrm{GO} / \mathrm{GCE}$ (curve d) in the absence of maltol were also studied, showing 
virtually featureless curves. This reveals that the oxidation peaks in Supplemental Fig. S2 are attributed to maltol.

The electrochemical responses of maltol were further examined using square wave voltammetry (SWV), and the results are displayed in Fig. 4A. In $\mathrm{pH} 8.2$ boric acid-borax buffer and after $60^{-} \mathrm{s}$ accumulation, one negligible oxidation peak is observed on the bare GCE (curve a), indicative of slow electron transfer, whereas the response is considerably improved by 2.2 times at $\mathrm{SnO}_{2} @ \mathrm{C} / \mathrm{GCE}$ (curve b). The enhancement in the peak current at the surface of $\mathrm{SnO}_{2} @ \mathrm{C}$ is due to the coating of carbon shell, the $\mathrm{SnO}_{2} @ \mathrm{C}$ core-shell structure can combine the merits of good contact and efficient diffusion distances for electron transport, which leads to fast reaction kinetics. However, it is necessary to be noted that the oxidation signal of maltol on the surface of $\mathrm{SnO}_{2} @ \mathrm{C} @ \mathrm{GO}$ is 5.0 times bigger than that on bare GCE (curve c). The result reveals that the incorporation of 2D GO sheets can significantly improve the electrochemical performance of $\mathrm{SnO}_{2} @ \mathrm{C}$ electrode. It may be resulted from the synergistic effect that the $\mathrm{SnO}_{2} @ \mathrm{C}$ nanospheres act as cores support to improve the 2D GO sheets stability and the 2D GO sheets serve as flexible coating and conductive network for $\mathrm{SnO}_{2} @ \mathrm{C}$ nanospheres. Furthermore, the 2D GO sheets protect against the volume changes of $\mathrm{SnO}_{2} @ \mathrm{C}$ nanospheres during electrochemical processes. Additionally, the SWV response of $\mathrm{SnO}_{2} @ \mathrm{C} @ \mathrm{GO} / \mathrm{GCE}$ in the absence of maltol is also studied (curve d), no oxidation wave is clearly observed. In conclusion, the comparisons of Supplemental Fig. S2 and Fig. 4A clearly suggest the potential of $\mathrm{SnO}_{2} @ \mathrm{C} @ \mathrm{GO}-$ based sensing platform for highly sensitive electrochemical detection.

\subsection{Electrochemical oxidation mechanism of maltol}

The electrochemical behaviors of maltol on $\mathrm{SnO}_{2} @ \mathrm{C} @ \mathrm{GO} / \mathrm{GCE}$ with different 
scan rates were examined using CV. As seen in Fig. 4B, an oxidation peak is observed for maltol, and the oxidation peak current $\left(I_{\mathrm{p}}, \mu \mathrm{A}\right)$ increases linearly with the scan rate $\left(v, \mathrm{mV} \mathrm{s}^{-1}\right)$ (Inset I of Fig. 4B). So the oxidation of maltol is an adsorption-controlled irreversible process. For the irreversible and adsorption-controlled oxidation reaction, the relationship between peak potential $\left(E_{\mathrm{p}}, \mathrm{V}\right)$ and scan rate can be expressed by the following Laviron's equation [Laviron, 1974]:

$$
E_{\mathrm{p}}=E^{0}+\left(\frac{R T}{\alpha n F}\right) \ln \left(\frac{R T k^{0}}{\alpha n F}\right)+\left(\frac{R T}{\alpha n F}\right) \ln v
$$

where $E^{0}$ is the formal potential, $\alpha$ is the electron-transfer coefficient, $n$ is the number of transferred electron, $k^{0}$ is the rate constant of heterogeneous electron transfer, and other symbols have their usual meanings. It can be found in the inset II of Fig. 4B that the $E_{\mathrm{p}}$ is proportional to $\ln v$, and the slope $R T / \alpha n F$ equals to 0.047 . So the value of $\alpha n$ is calculated to be 0.55 . Generally, $\alpha$ is considered to be 0.5 in an irreversible electrode reaction. Consequently, one electron is involved in the oxidation of maltol, consisting with the reported results [Chao et al., 2014; Ma et al., 2014].

The oxidation peak potentials of maltol in boric acid-borax buffer solutions with different $\mathrm{pH}$ values were studied to discuss the number of transferred protons. The results show that $E_{\mathrm{p}}$ moves negatively with increasing the $\mathrm{pH}$ value, and the slope value is $-60 \mathrm{mV} \mathrm{pH}{ }^{-1}$. This is close to the theoretical $-59 \mathrm{mV} \mathrm{pH}^{-1}$, indicating the equal number of transferred protons and electrons. Based on the above results, it can be concluded that the electrochemical oxidation of maltol is a one-electron and one-proton process:<smiles>Cc1occc(=O)c1O</smiles> 


\subsection{Optimization of parameters for maltol detection}

The oxidation behaviors of $5.0 \mu \mathrm{M}$ maltol in various media such as $\mathrm{pH} 2.6-5.4$ acetic acid-sodium acetate buffer, $\mathrm{pH}$ 5.8-8.0 phosphate buffer, $\mathrm{pH}$ 7.4-9.0 boric acid-borax buffer, $\mathrm{pH}$ 1.81-6.59 Britton-Robinson buffer, and $\mathrm{HCl}, \mathrm{H}_{2} \mathrm{SO}_{4}, \mathrm{HClO}_{4}$, $\mathrm{NaOH}$ solution, were studied by SWV. The excellent oxidation response is obtained in boric acid-borax buffer for maltol since the peak shape is well-defined. In boric acid-borax buffer, the oxidation peak currents of maltol on $\mathrm{SnO}_{2} @ \mathrm{C} @ \mathrm{GO} / \mathrm{GCE}$ increase gradually with $\mathrm{pH}$ value from 7.4 to 8.2 , and then gradually decrease with further increasing $\mathrm{pH}$ value to 9.0 (Supplemental Fig. S3). To achieve the high sensitivity, $\mathrm{pH} 8.2$ boric acid-borax buffer was used for the determination of maltol.

The effect of amount of $\mathrm{SnO}_{2} @ \mathrm{C} @ \mathrm{GO}$ suspension on the oxidation signals of 5.0 $\mu \mathrm{M}$ maltol was also investigated, as shown in Supplemental Fig. S4. The oxidation peak currents of maltol enhance significantly when improving the amount of $\mathrm{SnO}_{2} @ \mathrm{C} @ \mathrm{GO}$ suspension from 0 to $10 \mu \mathrm{L}$, due to the improved accumulation efficiency of maltol caused by $\mathrm{SnO}_{2} @ \mathrm{C} @ \mathrm{GO}$ adsorption. As further increasing the amount of $\mathrm{SnO}_{2} @ \mathrm{C} @ \mathrm{GO}$ suspension to $15 \mu \mathrm{L}$, the oxidation peak currents of maltol change slightly, indicative of a saturation status for maltol adsorption. So $10-\mu \mathrm{L}$ $\mathrm{SnO}_{2} @ \mathrm{C} @ \mathrm{GO}$ suspension was selected to modify the GCE surface.

In order to further improve the detection sensitivity, accumulation is a simple and effective approach, which mainly contains potential and time parameters. The oxidation peak currents of $5.0 \mu \mathrm{M}$ maltol were compared after $60 \mathrm{~s}$ accumulation under different potentials by SWV (Supplemental Fig. S5A). The peak currents almost keep constant as accumulation potential positively shifting from -0.2 to $0.4 \mathrm{~V}$, revealing that the accumulation potential causes no influence on the oxidation peak 
current of maltol at the $\mathrm{SnO}_{2} @ \mathrm{C} @ \mathrm{GO}$-modified GCE. Consequently, an open-circuit accumulation was performed.

The effect of accumulation time on the peak current of $5.0 \mu \mathrm{M}$ maltol was further explored (Supplemental Fig. S5B). The peak currents increase rapidly within the first $60 \mathrm{~s}$ and then level off, signifying that the accumulation of maltol is very rapid to reach saturation at the $\mathrm{SnO}_{2} @ \mathrm{C} @ \mathrm{GO}$ film.

\subsection{Chronocoulometry measurements}

In next study, chronocoulometry technique was used to determine the kinetics in the electro-oxidation of maltol at bare GCE and $\mathrm{SnO}_{2} @ \mathrm{C} @ \mathrm{GO} / \mathrm{GCE}$. According to the formula given by Anson [Anson, 1964]:

$$
Q=\frac{2 n F A c D^{1 / 2} t^{1 / 2}}{\pi^{1 / 2}}+Q_{\mathrm{dl}}+Q_{\mathrm{ads}}
$$

where $F$ is the Faraday constant, $A$ is the geometrical area of the GCE $\left(0.071 \mathrm{~cm}^{2}\right), c$ is the concentration of maltol $(10 \mu \mathrm{M}), D$ is the diffusion coefficient, $t$ is the time, $Q_{\mathrm{dl}}$ is the double-layer charge which can be eliminated by the subtraction of the background charge, $Q_{\text {ads }}$ is the Faradaic charge due to the oxidation of adsorbed maltol molecules. Other symbols have their usual meanings. The slope of the $Q-t^{1 / 2}$ plots can be expressed as $2 n F A c D^{1 / 2} / \pi^{1 / 2}$. Here, $n=1, \pi=3.14$, and the slope values are 0.328 and $1.361 \mu \mathrm{C} \mathrm{s}^{-1 / 2}$ for bare GCE and $\mathrm{SnO}_{2} @ \mathrm{C} @ \mathrm{GO} / \mathrm{GCE}$, respectively. The calculated values of $1.80 \times 10^{-5}$ and $3.09 \times 10^{-4}$ for $D$ and the values of 0.0506 and $0.399 \mu \mathrm{C}$ for $Q_{\text {ads }}$ at bare $\mathrm{GCE}$ and $\mathrm{SnO}_{2} @ \mathrm{C} @ \mathrm{GO} / \mathrm{GCE}$ can be obtained, respectively. According to the following equation

$$
Q_{\mathrm{ads}}=n F A \Gamma
$$

the surface coverage $(I)$ is $7.39 \times 10^{-12}$ and $5.82 \times 10^{-11} \mathrm{~mol} \mathrm{~cm}^{-2}$ for bare GCE and 
$\mathrm{SnO}_{2} @ \mathrm{C} @ \mathrm{GO} / \mathrm{GCE}$, respectively. The results give prominent evidence that the $\mathrm{SnO}_{2} @ \mathrm{C} @ \mathrm{GO}$ composite on electrode surface shows enlarged accumulation ability for maltol.

\subsection{Analytical performances}

The potential interferences for the detection of maltol were also studied. It is found that $2 \mathrm{mM} \mathrm{K}{ }^{+}, \mathrm{NO}_{3}{ }^{-}, \mathrm{Na}^{+}, \mathrm{Cl}^{-}, \mathrm{Ca}^{2+}, \mathrm{NH}_{4}{ }^{+}, \mathrm{HCO}_{3}{ }^{-}$, glucose, sucrose, starch, glycine, citric acid, tartaric acid; $1.5 \mathrm{mM} \mathrm{SO}{ }^{2-}, \mathrm{Mg}^{2+}, \mathrm{H}_{2} \mathrm{O}_{2} ; 0.5 \mathrm{mM} \mathrm{Al}^{3+}, \mathrm{Zn}^{2+} ; 0.1 \mathrm{mM}$ ascorbic acid and $10 \mu \mathrm{M}$ hydroquinone do not interfere with the oxidation signal of $1.0 \mu \mathrm{M}$ maltol (the peak current change is below 5\%).

The reproducibility between multiple $\mathrm{SnO}_{2} @ \mathrm{C} @$ GO/GCEs was evaluated by parallel determining the oxidation peak currents of $1.0 \mu \mathrm{M}$ maltol. The relative standard deviation (RSD) is below 4\% for ten $\mathrm{SnO}_{2} @ \mathrm{C} @ \mathrm{GO} / \mathrm{GCEs}$, suggesting excellent reproducibility and detection precision.

In order to evaluate the capability of the developed modified electrode in the detection of maltol, the response behaviors of maltol with different concentrations were examined. As shown in Fig. 5, the oxidation peak current of maltol on $\mathrm{SnO}_{2} @ \mathrm{C} @ \mathrm{GO} / \mathrm{GCE}\left(I_{\mathrm{p}}, \mu \mathrm{A}\right)$ is linear with its concentration $(c, \mu \mathrm{M})$ over the range from 0.08 to $10 \mu \mathrm{M}$. The linear regression equation is $I_{\mathrm{p}}=-0.0159+0.154 c$, and the correlation coefficient $(\mathrm{R})$ is 0.998 , revealing good linearity. After an accumulation of $60 \mathrm{~s}$, the detection limit is calculated to be $12 \mathrm{nM}$ based on three signal-to-noise ratio.

The analytical characteristics of the developed electrode are compared with those of previously reported maltol voltammetric methods. The comparison results are summarized in Supplemental Table 1. According to the data of the table, the 
represented analytical characteristics of our developed electrode are better or at least comparable with those of the other depicted electrodes. We highlight that the features of the proposed system are its precision, sampling throughput, low consumption of reagent and of sample solution, no need for a pretreatment step, and excellent repeatability.

\subsection{Practical application}

To evaluate the practical application of this new method, it was used to detect the content of maltol in different food samples including biscuit, beer, red wine and juice (Supplemental Fig. S6). Upon addition of $100 \mu \mathrm{L}$ sample solution into $5.0 \mathrm{~mL} \mathrm{pH} 8.2$ boric acid-borax buffer, the SWV curves were recorded from 0.1 to $0.9 \mathrm{~V}$ after $60-\mathrm{s}$ accumulation (curve a). The determination of each sample was performed six replicates, and the RSD was lower than $4 \%$, revealing good precision. The content of maltol was obtained by the standard addition method (curve b), and the results are listed in Table 1. Moreover, the values of recovery are also calculated to be over the range from 96.3 to $104 \%$, indicating that the newly-developed method is accurate and has promising application.

\section{Conclusion}

In summary, we have presented an effective method to prepare $\mathrm{SnO}_{2} @ \mathrm{C}$ core-shell nanospheres supported on graphene oxide $\left(\mathrm{SnO}_{2} @ \mathrm{C} @ \mathrm{GO}\right) . \mathrm{SnO}_{2}$ particles were encapsulated by carbon shell under one-step hydrothermal condition and then the wrapping of $\mathrm{SnO}_{2} @ \mathrm{C}$ by $\mathrm{GO}$ sheets was performed. The $\mathrm{SnO}_{2} @ \mathrm{C} @ \mathrm{GO}$ nanocomposite was employed as a new electrochemical enhanced material for the fabrication of electrochemical platform for determination of maltol in food, which 
showed good linear range $(0.08 \sim 10 \mu \mathrm{M})$ and low detection limit $(12 \mathrm{nM})$. We believe the proposed detection approach opens up a new electrochemical detection strategy, extends the application range of semiconductor materials, and sheds light on the further fusing of electrochemical technique and analytical methods.

\section{Acknowledgments}

This work was supported by the National Science Foundation of China (No. 61201091), the Program for University Key Scientific Research of Henan (No. 15A150025), the Key Scientific and Technological Project of Henan (No. 152102210341 and 162102210126), and the Science \& Technology Innovation

Talents in Universities of Henan Province (No. 16HASTIT004). The center of Analysis and Testing of Xinyang Normal University was also acknowledged for its help in the SEM and TEM observation.

\section{References}

Ahn, S. H., Kim, D. J., Chi, W. S., \& Kim, J. H. (2014). Hierarchical double-shell nanostructures of $\mathrm{TiO}_{2}$ nanosheets on $\mathrm{SnO}_{2}$ hollow spheres for high-efficiency, solid-state, dye-sensitized solar cells. Advanced Functional Materials, 24, $5037-5044$

Anson, F. C. (1964). Application of potentiostatic current integration to the study of the adsorption of cobalt(III)-(ethylenedinitrilo(tetraacetate)) on mercury electrodes. Analytical Chemistry, 36, 932-934.

Avila, M., Gonzalez, M. C., Zougagh, M., Escarpa, A., \& Rios, A. (2007). Rapid sample screening method for authenticity controlling vanilla flavors using a $\mathrm{CE}$ 
microchip approach with electrochemical detection. Electrophoresis, 28, $4233-4239$.

Chao, M. Y., \& Ma, X. Y. (2014). Electrochemical determination of maltol in food products using a poly(L-tryptophan) modified glassy carbon electrode. Russian Journal of Electrochemistry, 50, 1065-1071.

Das, B., Voggu, R., Routa, C. S., \& Rao, C. N. R. (2008). Changes in the electronic structure and properties of graphene induced by molecular charge-transfer. Chemical Communications, 41, 5155-5157.

Dermiki, M., Phanphensophon, N., Mottram, D., \& Methven, L. (2013). Contributions of non-volatile and volatile compounds to the umami taste and overall flavour of shiitake mushroom extracts and their application as flavour enhancers in cooked minced meat. Food Chemistry, 141, 77-83.

Di, J. W., Bi, S. P., \& Zhang, F. (2004). Electrochemical determination of maltol in beverages with glassy carbon electrode and its silica sol-gel modified electrode. Talanta, 63, 265-272.

Escuderos, M. E., Garcia, M., Jimenez, A., \& Horrillo, M. C. (2013). Edible and non-edible olive oils discrimination by the application of a sensory olfactory system based on tin dioxide sensors. Food Chemistry, 136, 1154-1159.

Gan, T., Lv, Z., Sun, J. Y., Shi, Z. X., \& Liu, Y. M. (2015). Preparation of graphene oxide-wrapped carbon sphere@silver spheres for high performance chlorinated phenols sensor. Journal of Hazardous Materials, 302, 188-197.

Gan, T., Shi, Z. X., Hu, D. Y., Sun, J. Y., Wang, H. B., Liu, Y. M. (2015). Synthesis of graphene oxide-wrapped core-shell structured carbon sphere@ $\mathrm{Al}_{2} \mathrm{O}_{3}$ as electrode material for voltammetric determination of butylated hydroxyanisole in food products. Ionics, 21, 2959-2968. 
Gan, T., Shi, Z. X., Wang, K. L., Sun, J. Y., Lv, Z., \& Liu, Y. M. (2015). Synthesis and characterization of mesoporous tin oxide-functionalized reduced graphene oxide nanoplatelets for ultrasensitive detection of guaiacol in red wines. Australian Journal of Chemistry, 69, 220-229.

Hu, Z. F., Yan, Z. X., Shen, P. K., \& Zhong, C. J. (2012). Nano-architectures of ordered hollow carbon spheres filled with carbon webs by template-free controllable synthesis. Nanotechnology, 23, 485404.

Huang, K. J., Shuai, H. L., \& Zhang, J. Z. (2016). Ultrasensitive sensing platform for platelet-derived growth factor BB detection based on layered molybdenum selenide-graphene composites and Exonuclease III assisted signal amplification. Biosensors and Bioelectronics, 77, 69-75.

Huang, K. J., Wang, L., Liu, Y. J., Gan, T., Liu, Y. M., Wang, L. L., \& Fan, Y. (2013). Synthesis and electrochemical performances of layered tungten sulfide-graphene nanocomposite as a sensing platform for catechol, resorcinol and hydroquinone. Electrochimica Acta, 107, 379-387.

Jiang, G., Lin, Z., Chen, C., Zhu, L., Chang, Q., Wang, N., Wei, W., \& Tang, H. (2011). $\mathrm{TiO}_{2}$ nanoparticles assembled on graphene oxide nanosheets with high photocatalytic activity for removal of pollutants. Carbon, 49, 2693-2701.

Kumar, R., Naqvi, S., Gupta, N., Gaurav, K., Khan, S., Kumar, P., Rana, A., Singh, R. K., Bharadwaj, R., \& Chand, S. (2015). Bulk synthesis of highly conducting graphene oxide with long range ordering. RSC Advances, 5, 35893-35898.

Laviron, E. (1974). Adsorption, autoinhibition and autocatalysis in polarography and in linear potential sweep voltammetry. Journal of Electroanalytical Chemistry and Interfacial Electrochemistry, 52, 355-393.

LeBlanc, D. T., \& Akers, H. A. (1989). Maltol and ethyl maltol-From larch tree to 
successful food additive. Food technology, 43, 78-84.

Liu, Q. N., Dou, Y. H., Ruan, B. Y., Sun, Z. Q., Chou, S. L., \& Dou, S. X. (2016). Carbon-coated hierarchical $\mathrm{SnO}_{2}$ hollow spheres for lithium ion batteries. Chemistry-A European Journal, 22, 5853-5857.

Ma, J., Zhang, B., Wang, Y. N., Hou, X. F., \& He, L. C. (2014). Determination of flavor enhancers in milk powder by one-step sample preparation and two-dimensional liquid chromatography. Journal of Separation Science, 37, 920-926.

Maslova, O. A., Ammar, M. R., Guimbretiere, G., Rouzaud, J. N., \& Simon, P. (2012). Determination of crystallite size in polished graphitized carbon by Raman spectroscopy. Physical Review B, 86, 134205.

Matthews, M. J., Pimenta, M. A., Dresselhaus, G., Dresselhaus, M. S., \& Endo, M. (1999). Origin of dispersive effects of the Raman D band in carbon materials. Physical Review B, 59, R6585-R6588.

Ma, X. Y., \& Chao, M. Y. (2013). Electrocatalytic determination of maltol in food products by cyclic voltammetry with a poly( $\mathrm{L}-$ phenylalanine $)$ modified electrode. Analytical Methods, 5, 5823-5829.

Ma, X. Y., \& Chao, M. Y. (2014). Rapid voltammetric determination of maltol in some foods and beverages using a poly(methylene blue)/graphene-modified glassy carbon electrode. Journal of Solid State Electrochemistry, 18, 621-628.

Ni, Y. N., Wang, Y., \& Kokot, S. (2008). Simultaneous kenetic-spectrophotometric determination of maltol and ethyl maltol in food samples by using chemometrics. Food Chemistry, 109, 431-438.

Ni, Y. N., Zhang, G. W., \& Kokot, S. (2005). Simultaneous spectrophotometric determination of maltol, ethyl maltol, vanillin and ethyl vanillin in foods by 
multivariate calibration and artificial neural networks. Food Chemistry, 89, $465-473$.

Qi, J. C., \& Zhou, H. M. (2005). Application of solid-phase microextraction and gas chromatography-mass spectrometry technique on analysis of volatile components in natural products. Journal of Xinyang Normal University (Natural Science Edition), 18, 471-474.

Qu, Y., Wang, H., Chen, H., Han, M. M., \& Lin, Z. D. (2016). Synthesis, characterization and sensing properties of mesoporous $\mathrm{C} / \mathrm{SnO}_{2}$ nanocomposite. Sensors and Actuators B-Chemical, 228, 595-604.

Risner, C. H., \& Kiser, M. J. (2008). High-performance liquid chromatography procedure for the determination of flavor enhancers in consumer chocolate products and artificial flavors. Journal of the Science of Food and Agriculture, 88, $1423-1430$.

Thomsen, C., \& Reich, S. (2000). Doable resonant Raman scattering in graphene. Physical Review Letters, 85, 5214-5217.

Voggu, R., Rout, C. S., Frankilin, A. D., Fisher, T. S., \& Rao, C. N. R. (2008). Extraordinary sensitivity of the electronic structure and properties of single-walled carbon nanotubes to molecular charge-transfer. Journal of Physical Chemistry C, $112,13053-13056$.

Zhang, P., Wang, L. J., Zhang, X., Shao, C. L., Hu, J. H., \& Shao, G. S. (2015). $\mathrm{SnO}_{2}-$ core carbon-shell composite nanotubes with enhanced photocurrent and photocatalytic performance. Applied Catalysis B-Environmental, 166-167, $193-201$.

Zhou, J., Zhang, K., Li, Y. M., Li, K. J., \& Ye, B. X. (2012). Study on the electrochemical properties of maltol at a carbon paste electrode and its analytical 
application. Analytical Methods, 4, 3206-3211.

Zhou, W. S., Li, C. H., Sun, C., \& Yang, X. D. (2016). Simultaneously determination of trace $\mathrm{Cd}^{2+}$ and $\mathrm{Pb}^{2+}$ based on $\mathrm{L}$-cysteine/graphene modified glassy carbon electrode. Food Chemistry, 192, 351-357.

Zhu, M. S., Chen, P. L., \& Liu, M. H. (2012). Ag/AgBr/graphene oxide nanocomposite synthesized via oil/water and water/oil microemulsions: A comparison of sunlight energized plasmonic photocatalytic activity. Langmuir, 28 , $3385-3390$. 


\section{Figure captions}

Fig. 1 Schematic representation of the fabrication of $\mathrm{SnO}_{2} @ \mathrm{C} @ \mathrm{GO}$ modified GCE.

Fig. 2 (A) Powder XRD of $\mathrm{SnO}_{2} @ \mathrm{C} @ G O$. (B) Raman spectra of $\mathrm{SnO}_{2} @ \mathrm{C}$ (a) and $\mathrm{SnO}_{2} @ \mathrm{C} @ \mathrm{GO}(\mathrm{b})$.

Fig.3 SEM (a,b) and TEM (c-f) images of $\mathrm{SnO}_{2} @ \mathrm{C}(\mathrm{c}, \mathrm{d})$ and $\mathrm{SnO}_{2} @ \mathrm{C} @ \mathrm{GO}(\mathrm{e}, \mathrm{f})$.

Fig.4 (A) SWV graphs of bare GCE (a), $\mathrm{SnO}_{2} @ \mathrm{C} / \mathrm{GCE}$ (b) and $\mathrm{SnO}_{2} @ \mathrm{C} @ \mathrm{GO} / \mathrm{GCE}$ (c) in $\mathrm{pH} 8.2$ boric acid-borax buffer containing $4.0 \mu \mathrm{M}$ maltol. Curve d corresponds to the SW voltammogram of $\mathrm{SnO}_{2} @ \mathrm{C} @ \mathrm{GO} / \mathrm{GCE}$ in a blank solution. Accumulation time $=60 \mathrm{~s}$, amplitude $=25 \mathrm{mV}$, frequency $=15 \mathrm{~Hz}$. (B) Cyclic voltammograms of 10 $\mu \mathrm{M}$ maltol in $\mathrm{pH} 8.2$ boric acid-borax buffer at $\mathrm{SnO}_{2} @ \mathrm{C} @ \mathrm{GO} / \mathrm{GCE}$ with different scan rates, including 100 (e), 125 (f), 150 (g), 175 (h), 200 (i), 225 (j) and 250 (k) mV $\mathrm{s}^{-1}$. Insets: linear relationship of $I_{\mathrm{p}}$ vs. $v(\mathrm{I})$ and $E_{\mathrm{p}} \mathrm{vs} . \ln v(\mathrm{II})$.

Fig. 5 SWVs of $\mathrm{SnO}_{2} @ \mathrm{C} @ \mathrm{GO} / \mathrm{GCE}$ in different concentrations of maltol: 0.08, 0.5, 1.0, 3.0, 5.0, 6.5, 8.0, $10 \mu \mathrm{M}$ (from a to h). The inset shows the calibration plot of maltol vs. peak current. 
Table 1 Detection and recovery of maltol in biscuit, beer, red wine and juice samples.

\begin{tabular}{cccccc}
\hline \multirow{2}{*}{ Sample } & \multicolumn{3}{c}{ Detection } & \multicolumn{3}{l}{ Recovery test } \\
\cline { 2 - 6 } & This method (M) & RSD (\%) & Spiked (M) & Found (M) & Recovery (\%) \\
\hline Biscuit & $1.85 \times 10^{-7}$ & 3.9 & $1.00 \times 10^{-7}$ & $1.01 \times 10^{-7}$ & 101 \\
Beer & $3.71 \times 10^{-7}$ & 3.0 & $3.00 \times 10^{-7}$ & $2.89 \times 10^{-7}$ & 96.3 \\
Red wine & $1.57 \times 10^{-7}$ & 2.7 & $3.00 \times 10^{-7}$ & $2.92 \times 10^{-7}$ & 97.3 \\
Juice & - & - & $5.00 \times 10^{-7}$ & $5.20 \times 10^{-7}$ & 104 \\
\hline
\end{tabular}

a Found $(\mathrm{M})$ : the found value $\left(c_{\mathrm{s}}^{\prime}\right)$ is calculated according to the equation: $\frac{I_{\mathrm{p} 2}}{I_{\mathrm{p} 1}}=\frac{c_{0}+c_{\mathrm{s}}^{\prime}}{c_{0}}$, where $I_{\mathrm{p} 1}$ and $I_{\mathrm{p} 2}$ correspond to the peak current of maltol before and after spiking. $c_{0}$ is the concentration of maltol that exists in original sample (i.e., column 2).

${ }^{\mathrm{b}}$ Recovery (\%): the recovery value is calculated through dividing $c_{\mathrm{s}}^{\prime}$ by the real spiked value ( $c_{\mathrm{s}}$, column 4$)$

Author's name: Tian Gan, Junyong Sun, Miaomiao Yu, Kaili Wang, Zhen Lv, Yanming Liu 
Figure 1

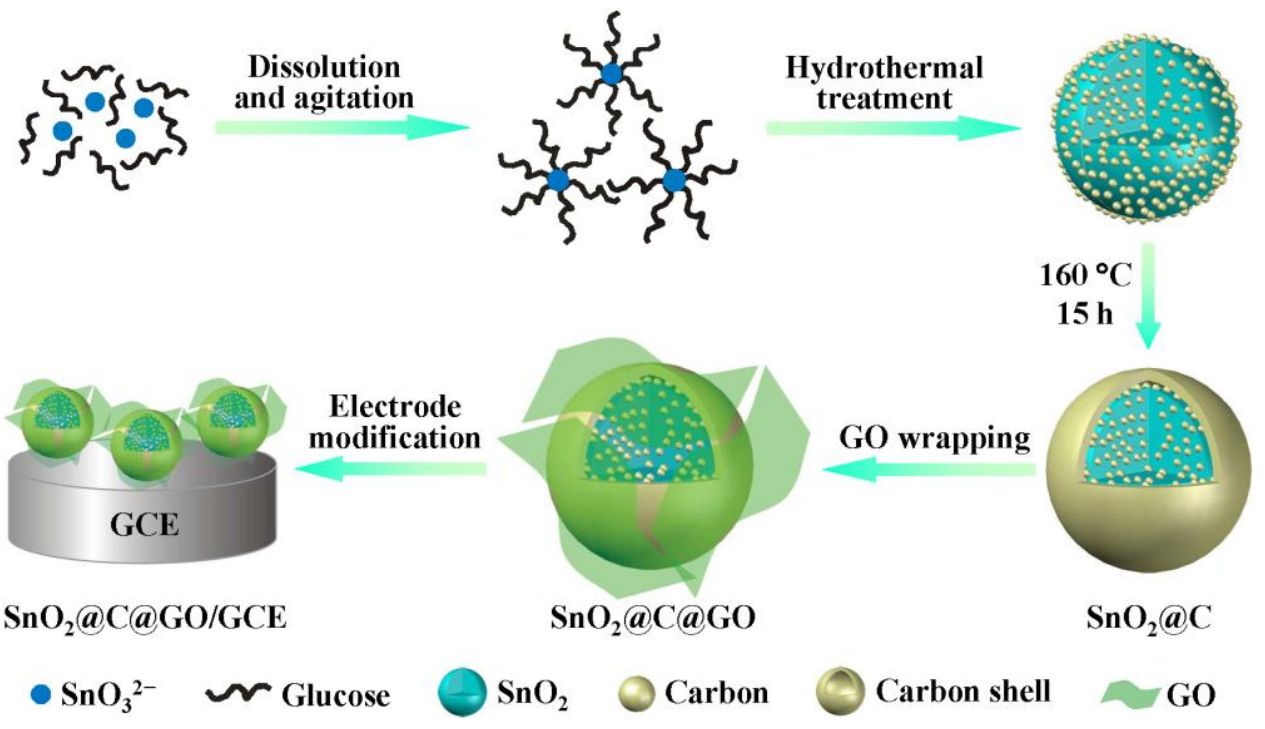

Author's name: Tian Gan, Junyong Sun, Miaomiao Yu, Kaili Wang, Zhen Lv, Yanming Liu 
Figure 2
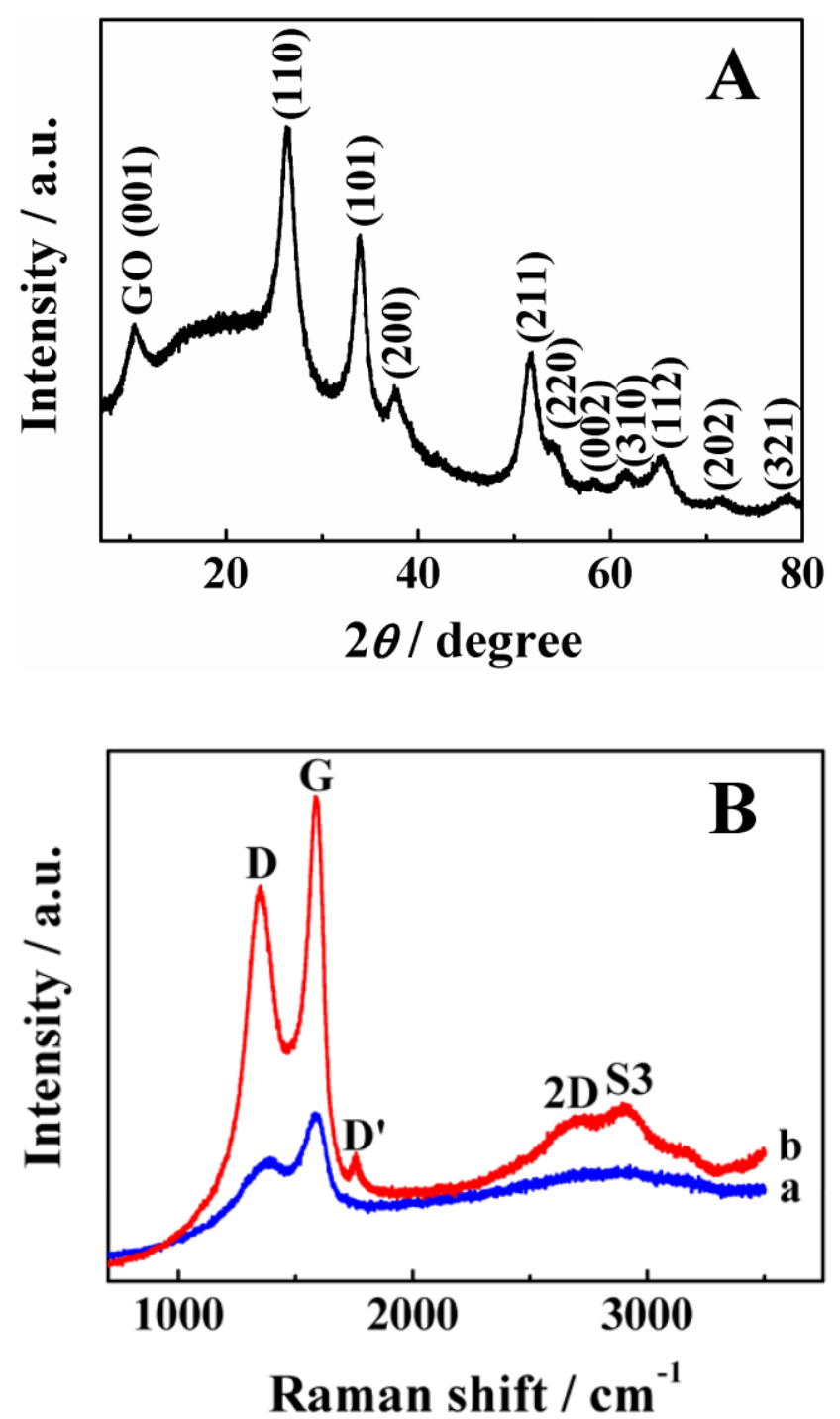

Author's name: Tian Gan, Junyong Sun, Miaomiao Yu, Kaili Wang, Zhen Lv, Yanming Liu 
Figure 3
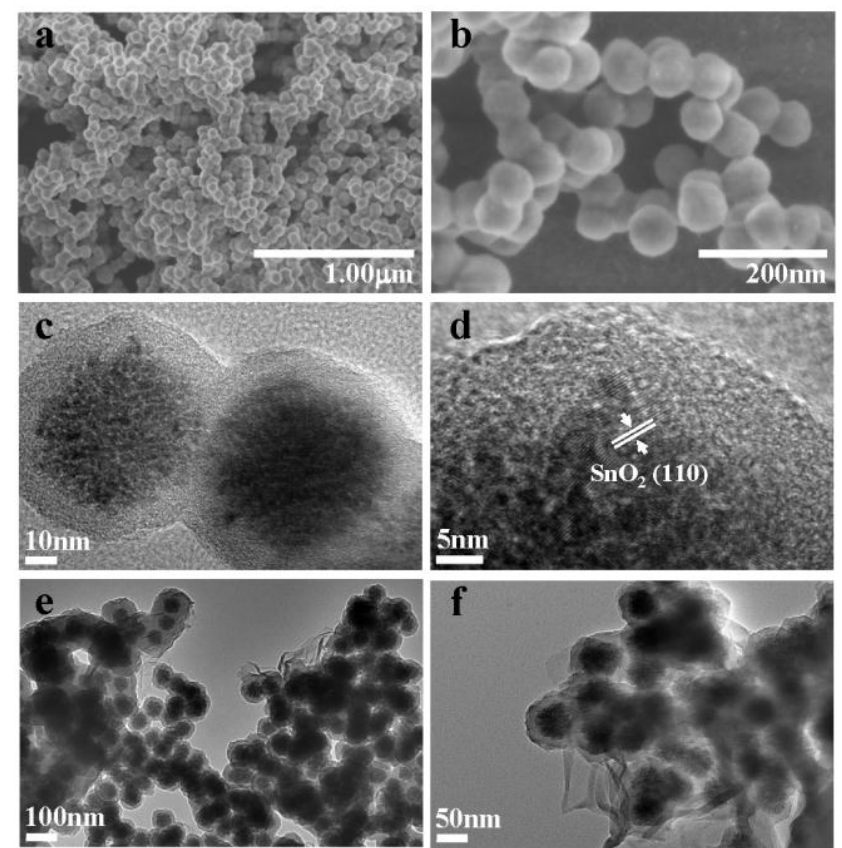

Author's name: Tian Gan, Junyong Sun, Miaomiao Yu, Kaili Wang, Zhen Lv, Yanming Liu 
Figure 4
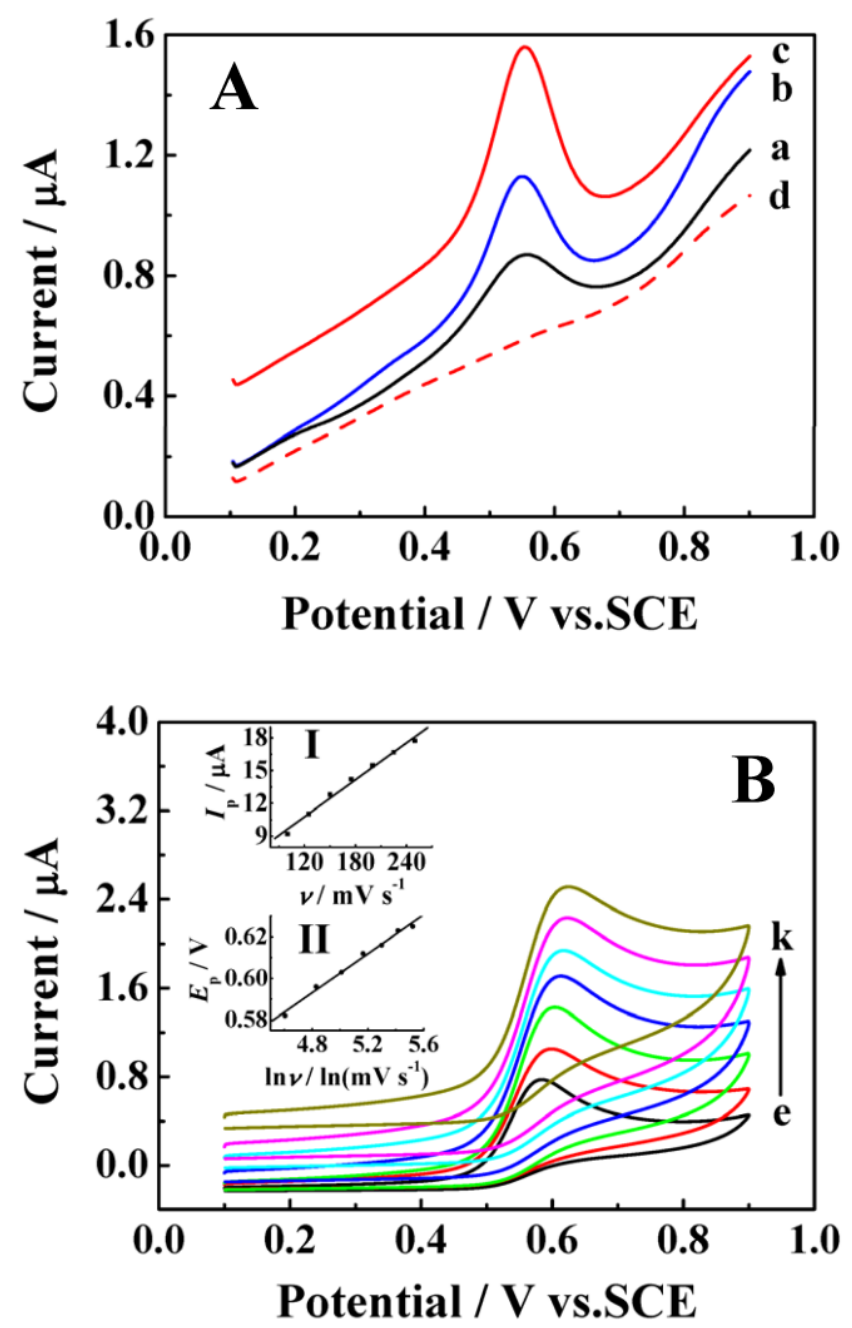

Author's name: Tian Gan, Junyong Sun, Miaomiao Yu, Kaili Wang, Zhen Lv, Yanming Liu 
Figure 5

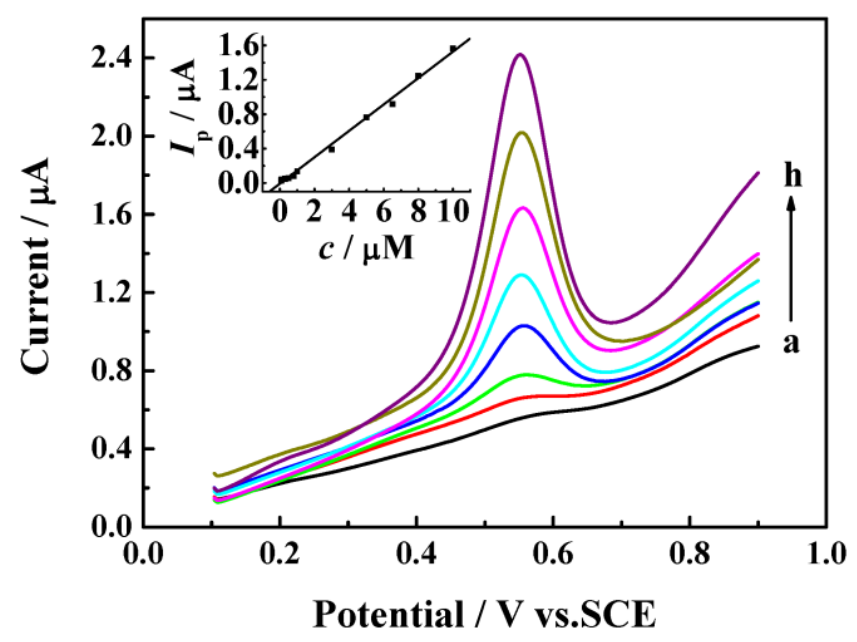

Author's name: Tian Gan, Junyong Sun, Miaomiao Yu, Kaili Wang, Zhen Lv, Yanming Liu 